\title{
Formação de Ferrita Delta na Soldagem de Aço Inoxidável Super Martensítico tipo CA6NM pelo Processo Plasma PTA
}

\author{
Lucas Behene ${ }^{1}$, Ramón S. Cortés Paredes² \\ 1 Universidade Federal do Paraná - UFPR, Programa de Pós-Graduação em Engenharia e Ciências dos Materiais, Curitiba, PR, Brasil. \\ 2 Universidade Federal do Paraná - UFPR, Laboratório de Aspersão Térmica e Soldagem Especiais - LABATS, Curitiba, PR, Brasil.
}

Recebido: 26 Abr., 2017

Aceito: 30 Out., 2017

E-mail: lucasbehene@gmail.com (LB)
Resumo: As pás de turbinas utilizadas na geração de energia em usinas hidrelétricas são fabricadas de aço inoxidável martensítico macio e estão sujeitas ao aparecimento de trincas pela presença da ferrita $\delta$. As trincas precisam ser reparadas e processos de soldagem são utilizados. A ferrita $\delta$ mostra-se prejudicial às propriedades de resistência ao impacto e à corrosão dos aços martensíticos macios. O presente trabalho estuda a presença dessa fase num aço martensítico macio soldado através do processo Plasma com alimentação de vareta. Foram retirados corpos de prova de uma pá de turbina fabricada de aço ASTM 743 tipo CA6NM que foram soldados com adição de eletrodo ER410NiMo. A soldagem foi realizada com multipasse e os parâmetros variados foram corrente, pós aquecimento e recuo do eletrodo. O objetivo é avaliar a presença da ferrita $\delta$ na microestrutura de solidificação e na zona termicamente afetada. A ferrita $\delta$ mostrou-se presente tanto no interpasse, como no cordão de solda e ZTA dos corpos de prova. Foi observado que a soldagem multipasse contribui para uma diminuição do teor da ferrita no metal de adição devido aos passes subsequentes e que a soldagem com maiores correntes apresentaram uma menor retenção da ferrita $\delta$ no metal de adição.

Palavras-chave: CA6NM; Plasma; multipasse; ferrita $\delta$.

\section{Formation of Delta Ferrite in Welding of Super Martensitic Stainless Steel type CA6NM by Plasma Process PTA}

\begin{abstract}
The blades of the turbines used in hydroelectric plants made of soft martensitic stainless steel are subject to the appearance of cracks. These discontinuities demand repairs and welding processes are used to do so. The $\delta$ ferrite shown to be detrimental to the properties of corrosion resistance and have a negative impact on the microstructure of a soft martensitic steel. This paper studies the presence of this phase in a soft martensitic stainless steel welded by Plasma arc welding process with feed. Specimens of a turbine blade made of steel ASTM 743 type CA6NM were removed and welded with addition of electrode ER410NiMo. The welding was performed with multipass and the varied parameters were current, post heating and indentation of the electrode. The objective is to evaluate the presence of $\delta$ ferrite in the microstructure. This phase was present both in the interpass, as in the weld and HAZ of the specimens. It was observed that the multipass welding contributes to a decrease in the content of ferrite in weld metal due to subsequent welding passes and with larger currents had lower retention of $\delta$ ferrite in the weld metal.
\end{abstract}

Key-words: CA6NM; Plasma; multipass; $\delta$ ferrite.

\section{Introdução}

A geração de energia no Brasil é altamente dependente das usinas hidrelétricas, sendo mais de $64 \%$ dessa energia proveniente desse tipo de usina [1]. As turbinas hidráulicas utilizam a energia potencial oferecida pela queda da água que é convertida em energia mecânica útil. Essas turbinas operam em regimes de alta e baixa carga e estão sujeitas a diferentes problemas: a cavitação e a ocorrência de trincas em regiões de alta concentração de tensões ou onde existem falhas de fundição ou soldagem. Além de causarem prejuízos devido ao comprometimento do material e da estrutura das pás, também há o prejuízo econômico decorrente da pausa para reparo, impedindo o funcionamento da turbina e o consequente fornecimento de energia.

O estudo está relacionado com a recuperação dessas trincas através do processo de soldagem Plasma por arco transferido (PTA). Na ultima década as pás das turbinas estão 
Formação de Ferrita Delta na Soldagem de Aço Inoxidável Super Martensítico tipo CA6NM pelo Processo Plasma PTA

sendo fabricadas de aço inoxidável martensítico macio ASTM 743 tipo CA6NM e pretende-se estudar a recuperação de trincas com a adição de um aço de composição similar, em forma de vareta, classificado como ER410NiMo.

Os aços inoxidáveis supermartensíticos (AISM) foram desenvolvidos buscando manter as propriedades de elevada dureza e resistência mecânica, assim como melhoria na resistência à corrosão e soldabilidade [2]. Os aços inoxidáveis martensíticos convencionais apresentam baixa soldabilidade e elevada susceptibilidade a trincas de hidrogênio, portanto, em busca de aumentar a soldabilidade desses aços, foi adicionada uma maior quantidade de Níquel (4,0 a 6,0\% em peso) para aumentar o campo austenítico, dessa forma foi possível então diminuir a quantidade de carbono presente nesses aços (máximo de 0,06\% em peso) [3]. Outros elementos também estão presentes nos aços inoxidáveis supermartensíticos. Alguns autores [2-4] afirmam que estes aços têm 12-13\% Cr, 2-5\% de Ni, 0,5-2,0\% de Mo.

Os AIMM solidificam a partir de cristais de ferrita $\delta$. Próximo de $1300{ }^{\circ} \mathrm{C}$ inicia-se a transformação desses cristais de ferrita em austenita $\gamma$, sendo que a transformação se completa por volta dos $1200^{\circ} \mathrm{C}$. No entanto, devido às altas velocidades de resfriamento durante o processo de soldagem, há a existência de um super-resfriamento da ferrita $\delta$ que não consegue tempo suficiente para se transformar em austenita $\gamma[3]$.

De modo similar, seguindo o resfriamento, a austenita $y$ se transforma em martensita, mas não por completo graças a essas altas velocidades de resfriamento. Portanto, ao final, a estrutura de um aço inoxidável martensítico macio é composta de uma matriz de martensita, com uma quantidade de ferrita $\delta$ e até $20 \%$ de austenita [ $\gamma$ ] retida. Essa austenita tem papel importante no aumento da tenacidade desse aço. A Figura 1 mostra o diagrama Fe-Cr-Ni onde a linha hachurada mostra a localização dos AIMM.

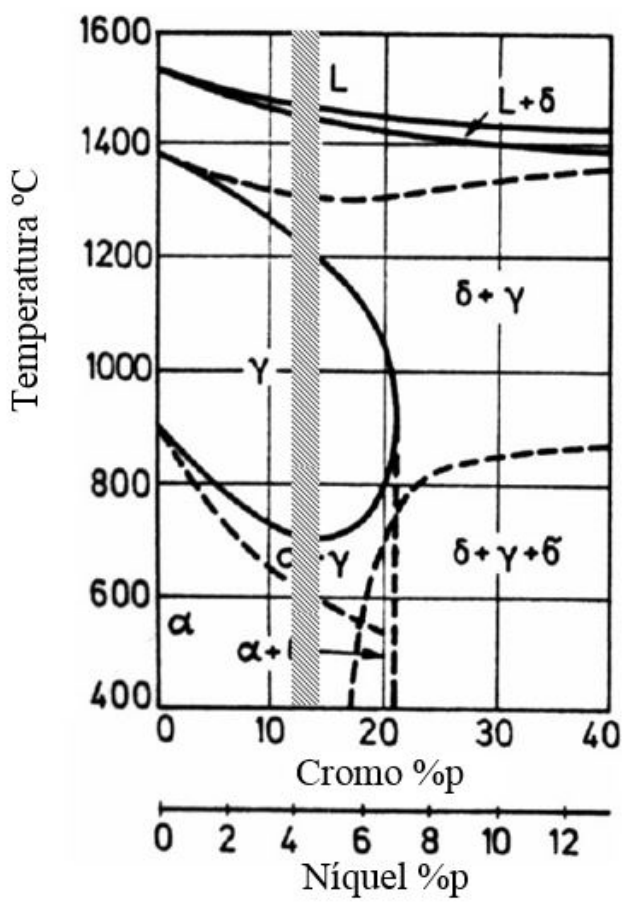

Figura 1. Diagrama pseudo-binário Fe-Cr-Ni, onde a área (linha escura) representa a localização dos aços inoxidáveis supermartensíticos (AISM) [3].

A presença da fase ferrita $\delta$ nos AISM ainda é objeto de estudos. Segundo Carrouge [4], a presença dessa fase, de uma maneira geral, é indesejável. O mesmo autor demonstra que a presença de $14 \%$ de ferrita $\delta$ na matriz martensítica, elevou a temperatura dútil frágil (TTDF) de $-96^{\circ} \mathrm{C}$ para $-43^{\circ} \mathrm{C}$. Os autores Sanches-Cabrera et al. [5] também investigaram a presença dessa fase nos aços inoxidáveis, e afirmaram que a ferrita $\delta$ presente na zona termicamente afetada (ZTA) de um aço inoxidável, influenciou de forma negativa na propagação de trincas por 
fadiga, atribuindo esse comportamento a uma susceptibilidade de fragilização por hidrogênio experimentado por essa fase.

Wang et al. [6], compararam valores de ensaio Charpy de aços CA6NM que possuíam, respectivamente, estrutura isenta de ferrita e estrutura contendo $7,8 \%$ dessa fase e encontraram uma diminuição de valores de 215J 103J. Os mesmos autores, através de espectroscopia de energia dispersiva (EDS), demonstraram na região da fratura a presença da ferrita $\delta$, pois esta possui uma maior quantidade de Cromo e de Molibdênio que a matriz martensítica (17,8\% de $\mathrm{Cr}$ e 2,6\% de Mo para as ilhas de ferrita e $13 \% \mathrm{Cr}$ e $1 \%$ de Mo para a matriz de martensita), provando que a trinca se deu na região das ilhas de ferrita $\delta$.

Henke et al. [7] através de análises efetuadas sobre corpos de prova fabricados com aço CA6NM onde foi realizada uma refusão com tocha plasma nas condições de corrente contínua e polaridade direta (CC-), mostrou que a nucleação do processo de fadiga ocorria em regiões contendo ferrita $\delta$ em associação à presença de ripas de martensita orientadas a $45^{\circ}$ em relação à direção da solicitação de esforços.

A Figura 2 mostra a presença da ferrita $\delta$ em um AISM soldado com adição de ER410NiMo próximo da linha de fusão (LF).

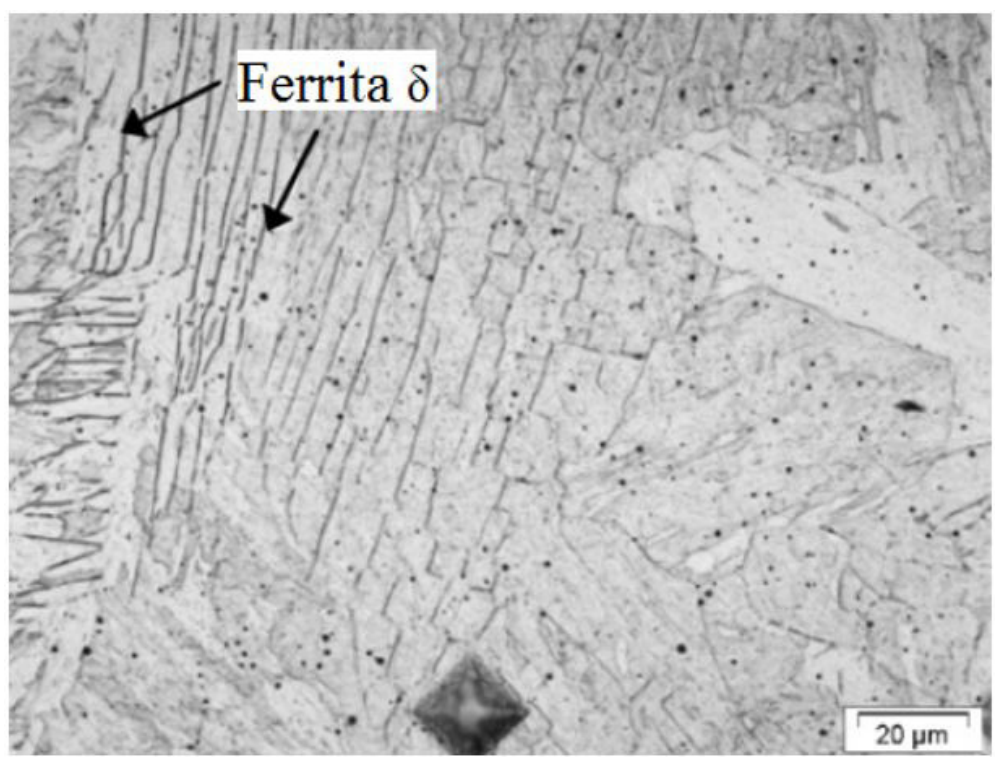

Figura 2. Micrografia da região soldada de um AISM com adição de ER410NiMo próxima a LF mostrando a presença da ferrita $\delta[8]$.

Também, Ferreño et al. [9] detectaram a presença de várias trincas ao longo de ilhas de grãos de ferrita $\delta$ de um aço CA6NM retirado de uma pá de turbina tipo Pelton, indicando uma certa relação entre a presença dessa fase com a nucleação das trincas no material.

\section{Materiais e Métodos}

Para avaliar a soldabilidade do aço AISM foram soldados nove corpos de prova (CP) com diferentes parâmetros de soldagem, sendo depositados numa primeira camada quatro cordões de solda, numa segunda camada três cordões, e a última camada dois cordões de solda. Os parâmetros da soldagem variados foram corrente, pós aquecimento ou tratamento térmico pós soldagem (TTPS) e recuo do eletrodo na tocha plasma. A combinação desses parâmetros foi determinada através de um arranjo de Taguchi para três fatores, variando os parâmetros em três níveis diferentes, resultando num arranjo L9, ou seja, 9 experimentos, como mostrado na Tabela 1. Na Tabela 2 observam-se os parâmetros fixos para a soldagem dos 9 experimentos. 
Formação de Ferrita Delta na Soldagem de Aço Inoxidável Super Martensítico tipo CA6NM pelo Processo Plasma PTA

Tabela 1. Parâmetros variados para a soldagem realizada com corrente contínua.

\begin{tabular}{cccc}
\hline Corpos de Prova & Corrente (A) & Pós Aquecimento TTPS $\left({ }^{\circ} \mathbf{C}\right)-\mathbf{~} \mathbf{h}$ & Recuo do Eletrodo na Tocha PTA (mm) \\
CP1 & 160 & TA & 0,4 \\
CP2 & 160 & 550 & 0,8 \\
CP3 & 160 & 600 & 1,2 \\
CP4 & 180 & 600 & 0,4 \\
CP5 & 180 & TA & 0,8 \\
CP6 & 180 & 550 & 1,2 \\
CP7 & 200 & 550 & 0,4 \\
CP8 & 200 & 600 & 0,8 \\
CP9 & 200 & TA & 1,2 \\
\hline
\end{tabular}

Tabela 2. Parâmetros fixos para a soldagem.

\begin{tabular}{cc}
\hline Velocidade de soldagem & $150 \mathrm{~mm} / \mathrm{min}$ \\
Distância bico de contato peça & $10 \mathrm{~mm}$ \\
Vazão do gás de plasma & $2,0 \mathrm{l} / \mathrm{min}$ \\
Vazão do gás de proteção & $11,0 \mathrm{I} / \mathrm{min}$ \\
Temperatura de Pré-aquecimento & $80^{\circ} \mathrm{C}$ \\
Temperatura de interpasse & $80^{\circ} \mathrm{C}$ \\
Diâmetro da vareta & $2,4 \mathrm{~mm}$ \\
\hline
\end{tabular}

Para a seleção dos três níveis da corrente foram realizados testes preliminares até serem obtidas as condições de estabilidade do arco para uma alimentação do eletrodo em forma de vareta, que foi realizada manualmente.

Os níveis para a faixa de temperatura do TTPS baseiam-se em trabalhos como de Brezina [10] que mostrou que acima de $550{ }^{\circ} \mathrm{C}$ existe o aparecimento de uma austenita estável e finamente distribuída no interior da microestrutura. Essa austenita é desejável pois aumenta a tenacidade do aço ASTM743 tipo CA6NM, melhorando seu desempenho com relação aos testes de impacto. Também foi evidenciado que acima dos $620^{\circ} \mathrm{C}$ há o surgimento de uma austenita instável, ou seja, que se transforma em martensita não revenida novamente durante o resfriamento, portanto para fins de comparação foi estabelecido trabalhar com e sem TTPS, nas faixas apresentadas na Tabela 1.

Os parâmetros fixados, apresentados na Tabela 2, foram baseados em outros trabalhos que estudaram aços de composição similares. A temperatura de interpasse foi estudado por Rubens de Gouveia et al. [11], que compararam temperaturas de $80^{\circ} \mathrm{Ce} 150^{\circ} \mathrm{C}$, onde a primeira apresentou melhor resultado nos ensaios de tenacidade à fratura.

Foi percebido que para a temperatura interpasse de $80^{\circ} \mathrm{C}$, a morfologia da ferrita $\delta$ era diferente da observada para a temperatura de interpasse de $150^{\circ} \mathrm{C}$. Isso se deve ao fato de que com a temperatura mais baixa, a ferrita $\delta$ se forma entre 1200 e $1300^{\circ} \mathrm{C}$, no chamado campo bifásico $\gamma+\delta$, e sua dispersão na matriz de martensita se da de forma intergranular. Para a temperatura de interpasse mais alta, ou seja, a $150{ }^{\circ} \mathrm{C}$ a ferrita $\delta$ se dispersou entre as placas de austenita de Widmanstätten, formação característica do campo monofásico $\delta$, onde ocorre a completa transformação da austenita em ferrita, entre 1300 e $1450{ }^{\circ} \mathrm{C}$.

Essa morfologia, segundo os autores, demonstrou baseado nos ensaios de tenacidade, que a ferrita proveniente do campo bifásico, ou seja, a que se dispersa de forma intergranular, não apresenta significativa influência na tenacidade do material. Portanto, essa formação e dispersão de ferrita $\delta$, quando comparada ao material com teores quase zero dessa fase, não afeta muito o comportamento com relação a tenacidade à fratura. Já a ferrita $\delta$ proveniente do campo monofásico mostrou-se prejudicial para essa propriedade do metal, diminuindo significativamente os valores comparados ao material isento de ferrita.

O diâmetro da vareta foi escolhido com base num melhor aspecto visual do cordão de solda, os testes foram feitos para diâmetros de 2,4 e 3,2 mm, sendo escolhida a vareta de 2,4 mm que resultou em maior homogeneidade dos cordões. 
A distância bico de contato peça (DBCP) foi determinada com base também em testes preliminares, sendo outras distâncias avaliadas ( $8 \mathrm{~mm}$ a $16 \mathrm{~mm}$, com incremento de $2 \mathrm{~mm}$ ) e, como sugere a literatura de Reis e Scotti [12], não foram evidenciadas grandes diferenças na largura e penetração da solda, visto que o arco plasma passa por uma constrição que aumenta muito sua velocidade e o parâmetro DBCP não exerce significativa influência na largura ou na penetração. $O$ valor de $10 \mathrm{~mm}$ foi fixado baseando-se então no trabalho de Henke [13] que utilizou o plasma PTA para fazer refusão de um aço de composição química muito semelhante ao empregado neste trabalho.

Com o objetivo de obter as condições de resfriamento equivalente à soldagem numa pá de turbina de grande tamanho, foi utilizado um gabarito de soldagem que resfria o CP simultaneamente com a soldagem. Esse dispositivo é composto de uma base oca, por onde passa água proveniente de um Cooler. O dispositivo de resfriamento é mostrado na Figura 3.

As dimensões dos CP foram de $80 \times 55 \times 12,5 \mathrm{~mm}$ como observado na Figura 4.

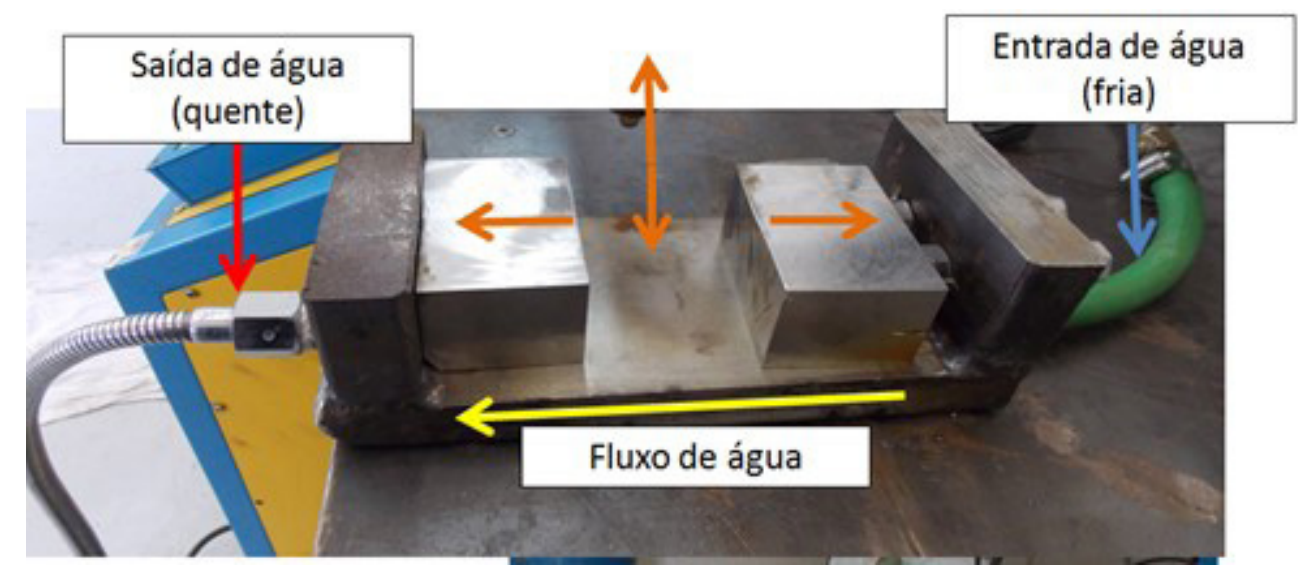

Figura 3. Gabarito utilizado para resfriar os corpos de prova durante a soldagem, as setas laranjas representam os sentidos de troca de calor da peça no gabarito.

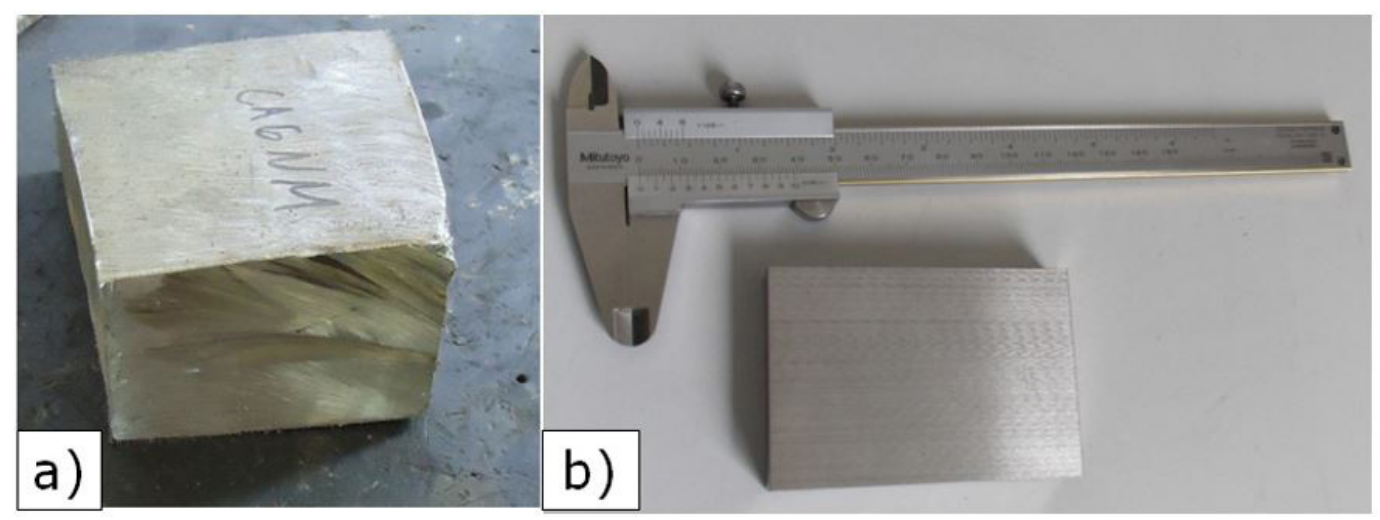

Figura 4. (a) Aspecto do tarugo logo que retirado de uma pá de aço tipo CA6NM; (b) Aspecto final do CP.

Na Figura 5 pode-se observar a técnica de soldagem PTA com tocha de avanço automático e alimentação manual da vareta, assim como o aspecto final do CP após serem feitos todos os passes de soldagem.

Após finalizada a soldagem dos $\mathrm{CP}$, foi analisada a presença da ferrita $\delta$ tanto no metal de adição quanto na zona termicamente afetada (ZTA) de cada um. Para isso, foram utilizados diferentes reagentes químicos (vide Tabela 3) e a microestrutura foi observada através do microscópio óptico (MO). A quantidade de $\delta$ presente em cada CP foi avaliada pelo software ANALYSIS através da binarização da imagem, como mostrado na Figura 6 . 


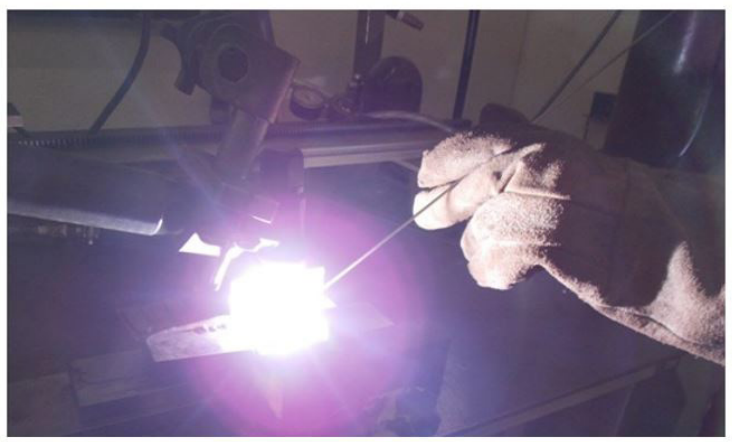

(a)

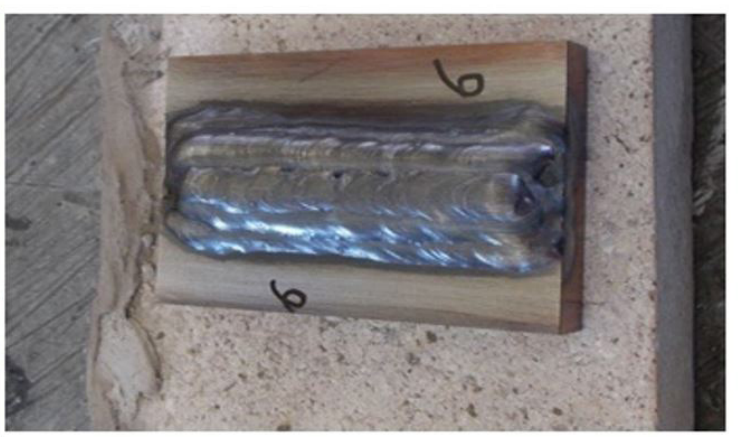

(b)

Figura 5. (a) Soldagem plasma PTA mostrando a alimentação com a vareta utilizada para a confecção dos cordões; (b) Aspecto final do CP após feitos todos os passes de soldagem.

a)

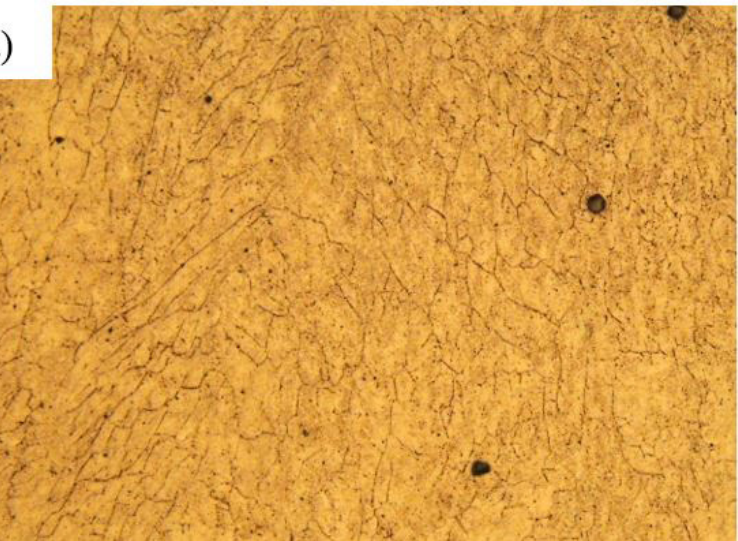

b)

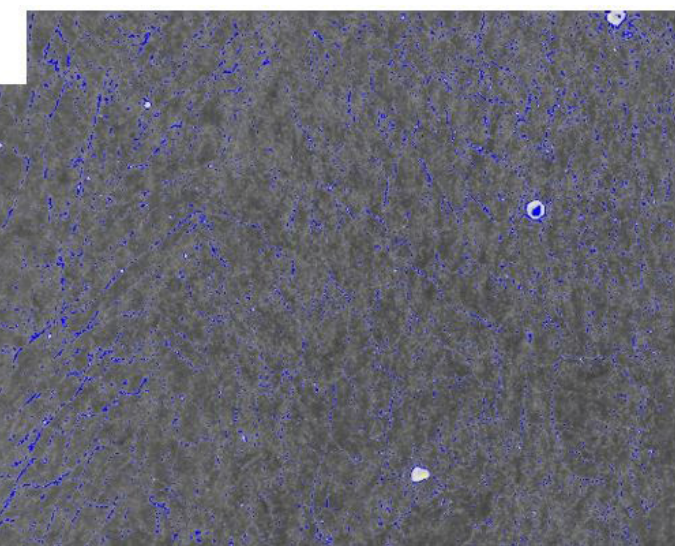

Figura 6. Exemplo de binarização da imagem para estimativa da presença da ferrita $\delta$ (em azul). Imagem sem binarização em (a) e imagem binarizada em (b).

Tabela 3. Reagentes químicos utilizados para o procedimento de observação microestrutural.

\begin{tabular}{cccc}
\hline Nome & Reagentes & Procedimento & Especificidade \\
Sulfúrico & $20 \mathrm{ml} \mathrm{H}_{2} \mathrm{SO}_{4}$ & Imersão da amostra e ataque & Revela ferrita $\delta$, mas não a martensita \\
& $0,01 \mathrm{~g} \mathrm{NH}_{4} \mathrm{CNS}$ & eletroquímico por 20s a $4 \mathrm{~V}$ & \\
\multirow{4}{*}{ Stock } & $80 \mathrm{ml} \mathrm{H}^{2} \mathrm{O}$ & & \\
& $1 \mathrm{~g} \mathrm{~K}_{2} \mathrm{O}_{5}$ & Imersão da amostra até atingir a coloração & Revela martensita em laranja e ferrita $\delta$ \\
& $20 \mathrm{ml} \mathrm{HCl}^{2}$ & vermelha & em azul \\
& $80 \mathrm{ml} \mathrm{H}_{2} \mathrm{O}$ & vela & \\
\hline
\end{tabular}

As linhas em azul representam a ferrita $\delta$. Através desse método foi então feita uma estimativa da porcentagem dessa fase presente em cada CP. Essa quantidade foi analisada através do método estatístico de Taguchi, sendo então avaliados quais dos parâmetros utilizados promoveram uma menor retenção de ferrita.

A dureza do material foi medida com o auxílio de um microdurômetro da marca Shimadzu. A carga aplicada foi de 300 gr por 15 segundos. O levantamento dos valores de dureza foi feito no centro dos CP (Figura 7), e foram medidos 80 valores de microdureza para cada CP com o intuito de verificar a manutenção ou variação desses valores em função de sobrepasse e de formação de fases diferentes da martensita. 


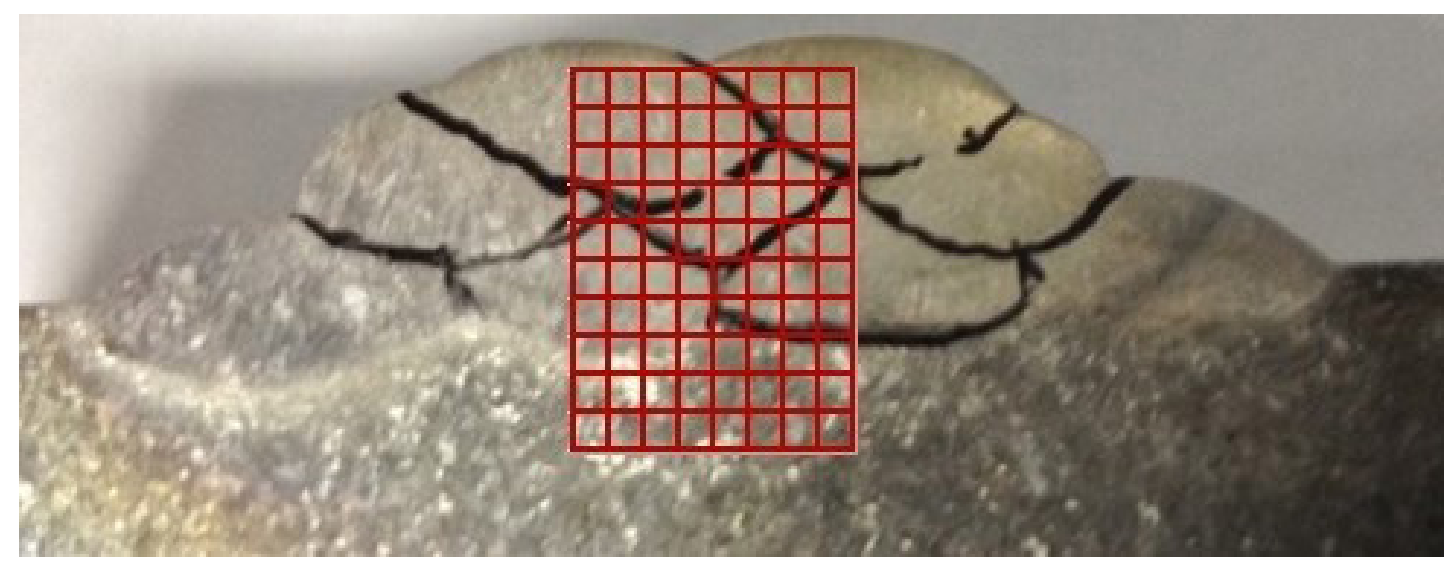

Figura 7. Representação da matriz de dureza, onde a grade em vermelho demonstra os locais de onde foram medidos os valores de microdureza.

\section{Resultados e Discussão}

Na Figura 8, observa-se uma inspeção visual após o ensaio de líquidos penetrantes dos CP2 e CP5. As figuras mostram que não houve presença de descontinuidades abertas na superfície como poros nem trincas.

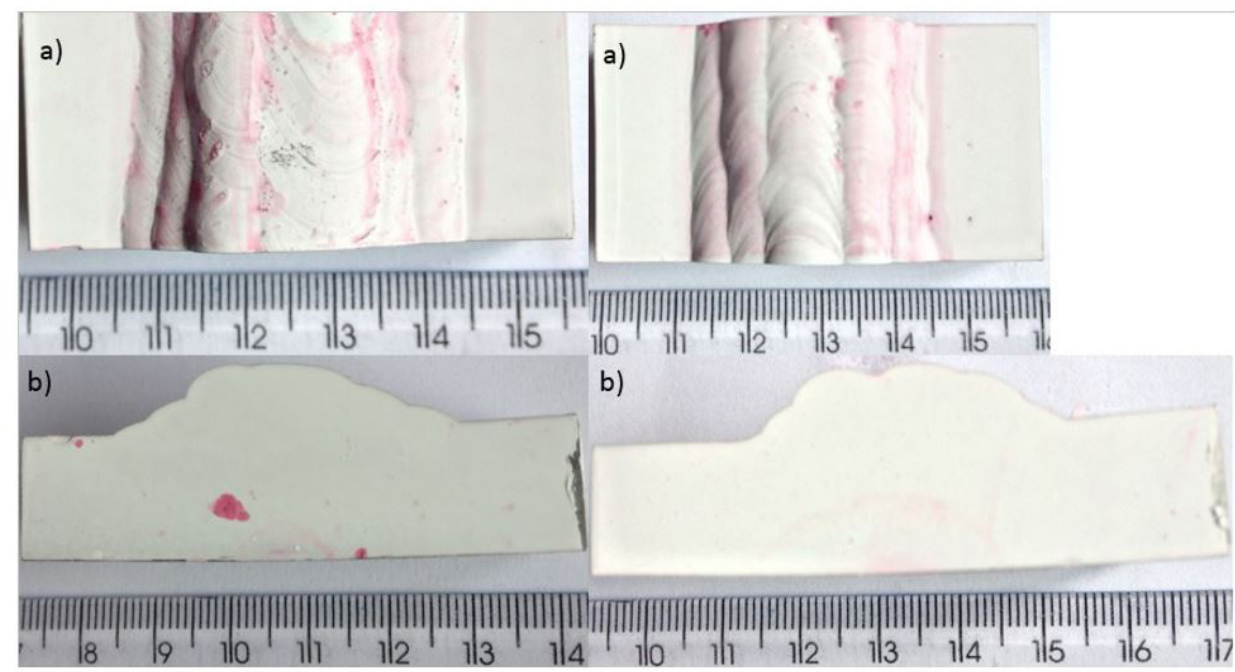

A

B

Figura 8. (A) inspeção visual por líquido penetrantes do CP2; (a) vista de topo; (b) vista da seção transversal; soldagem com 200A, recuo eletrodo de $0,8 \mathrm{~mm}$, preaquecimento de $150^{\circ} \mathrm{C}$ e TTPS de $550^{\circ} \mathrm{C}$; (B) inspeção visual por líquido penetrantes do CP5; (a) vista de topo; (b) vista da seção transversal; soldagem com 180A, recuo de $0.8 \mathrm{~mm}$, preaquecimento de $200^{\circ} \mathrm{C}$ e TTPS a TA.

$\mathrm{Na}$ avaliação da formação da ferrita $\delta$ realizada através de $\mathrm{MO}$, é percebida na Figura 9 a presença mais concentrada dessa fase próximas às linhas de fusão, entre um passe e outro da soldagem.

Esse comportamento se repete para todas os CP (Figura 10) independente do conjunto de parâmetros adotados. A presença da $\delta$ na região de interpasse se dá principalmente devido à temperatura de pico que a região próxima da linha de fusão atinge, sendo essa temperatura suficientemente alta para obter a formação desta fase.

Henke [13] observou um comportamento semelhante para a soldagem sem material de aporte com corrente pulsada, sendo a ferrita $\delta$ presente na forma de bandas, concentrando-se nas regiões onde o pico de corrente era dado. Isso provocava um chamado "bandeamento" dessa fase na estrutura. 
Formação de Ferrita Delta na Soldagem de Aço Inoxidável Super Martensítico tipo CA6NM pelo Processo Plasma PTA

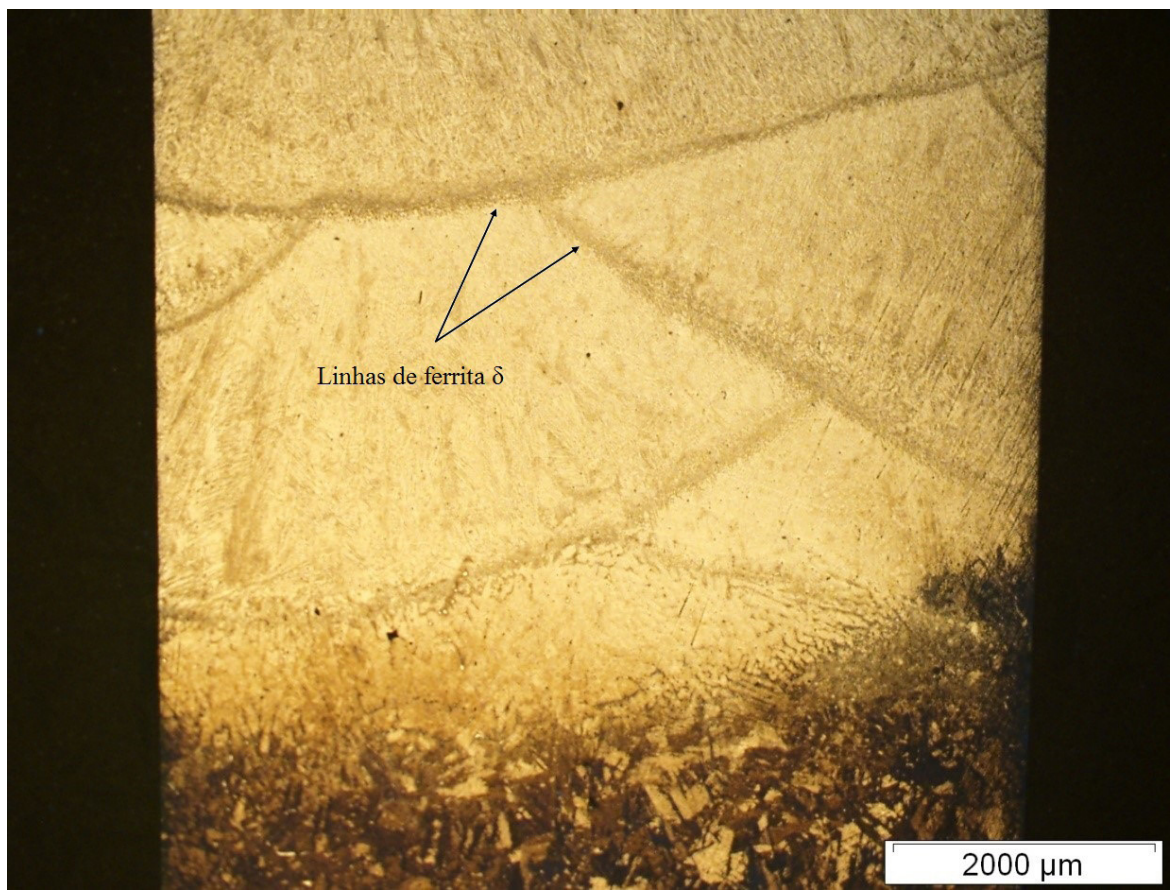

Figura 9. Aspecto do CP3 após ataque eletrolítico. As flechas apontam as linhas de ferrita $\delta$. Ataque: sulfúrico.
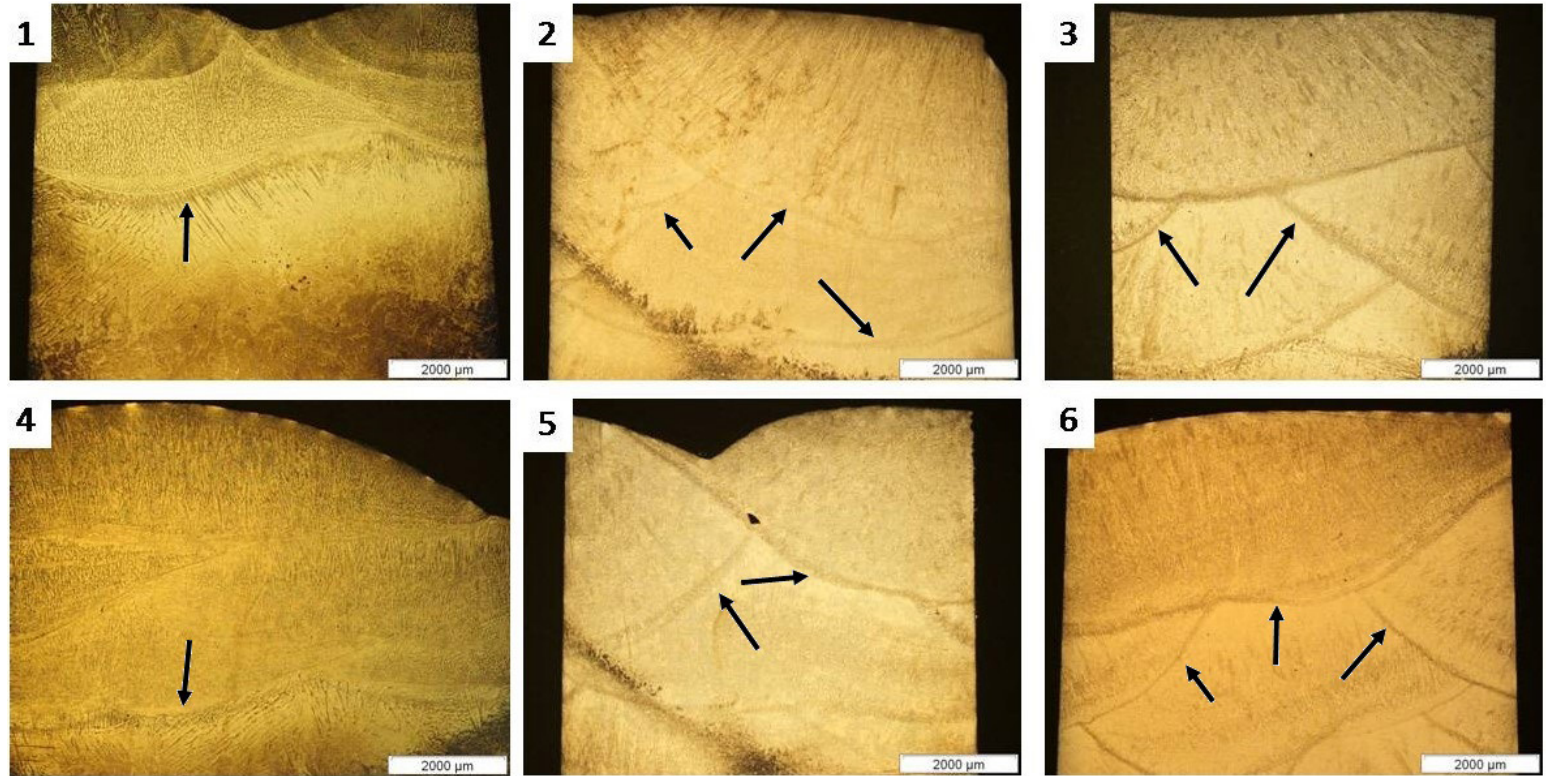

6
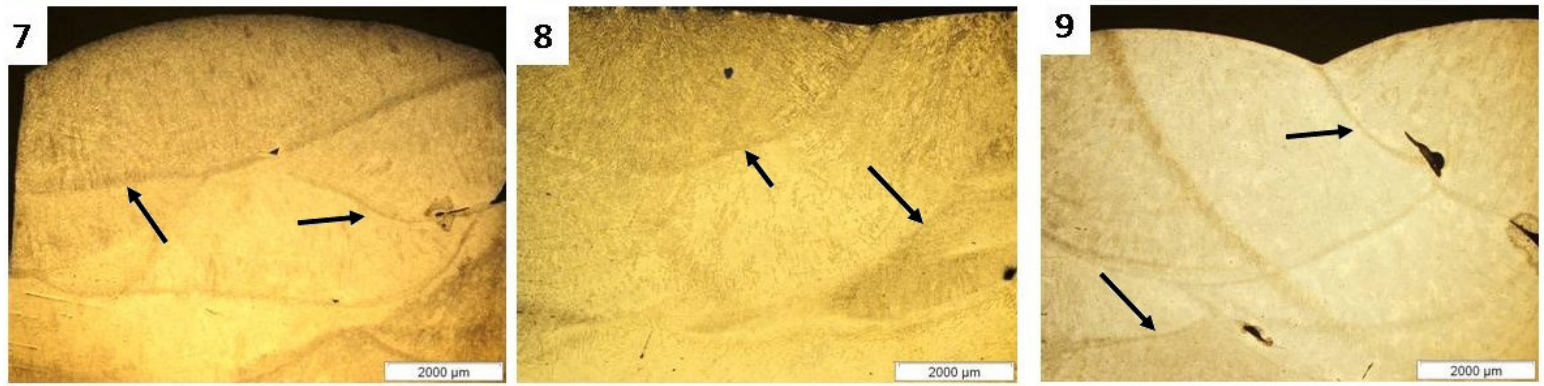

Figura 10. Aspecto dos $9 \mathrm{CP}$, as linhas apontam para o bandeamento da ferrita $\delta$. Ataque: sulfúrico. 
A Figura 11 mostra em detalhe o local onde se encontra o bandeamento da ferrita $\delta$ no CP5.

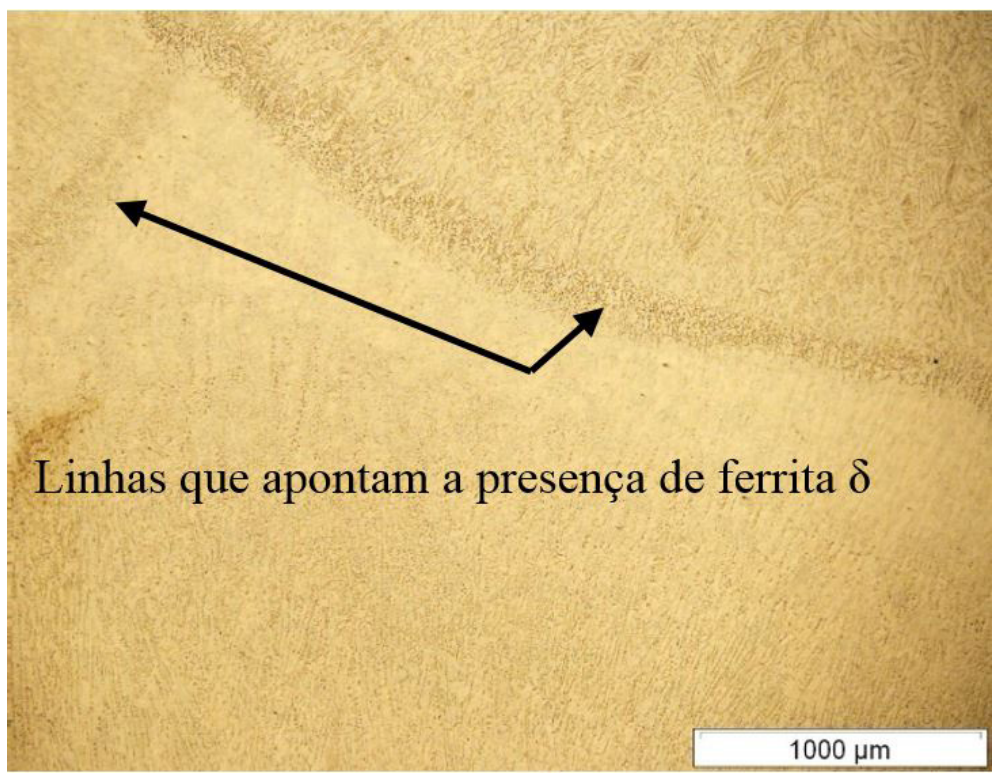

Figura 11. Bandeamento da ferrita $\delta$ do CP5, ampliação de 5x. Ataque: sulfúrico.

Para a visualização e confirmação da presença da ferrita $\delta$ nessas regiões, foi feito o ataque químico com o reagente Stock, que revela a ferrita com a cor azul. O resultado desse ataque é mostrado na Figura 12.

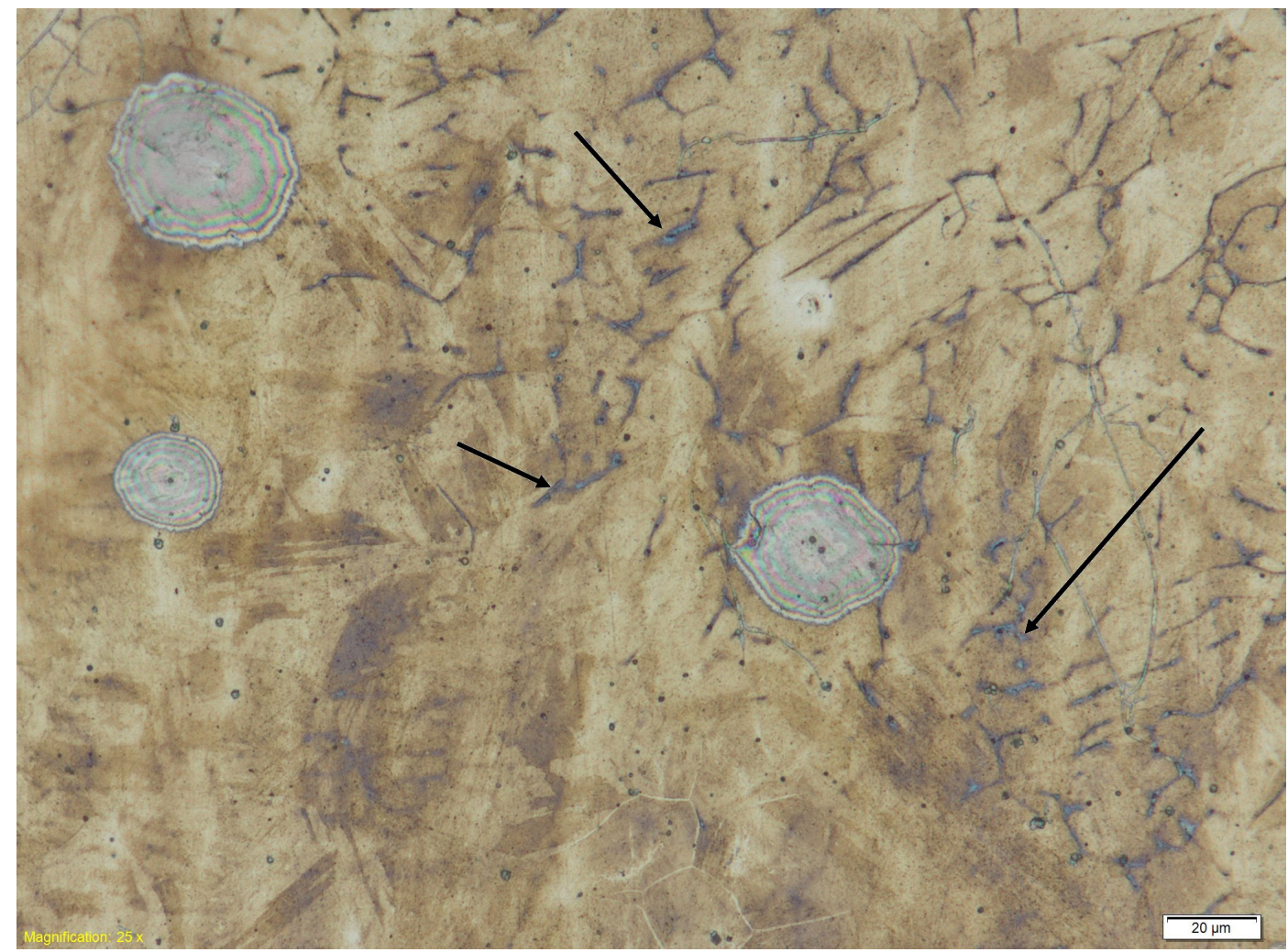

Figura 12. Presença da ferrita $\delta$ (em azul, apontada pelas flechas) no interpasse do CP5. Ampliação de 50x. As manchas arredondadas são resquícios de ataque químico que não foram possíveis de remover. Ataque: Stock. 
Através desse ataque foi mostrado que a ferrita está presente na região de interpasse dos CP. Outro lugar onde a ferrita $\delta$ está em maior quantidade é na zona termicamente afetada de dupla fase (ZTA-DF), também citada por outros autores em trabalhos que estudaram o aço CA6NM [4,13]. Além da ZTA-DF, foi possível identificar a ferrita também a zona termicamente afetada de granulação grosseira (ZTA-GG). A Figura 13 mostra essas regiões no CP1.

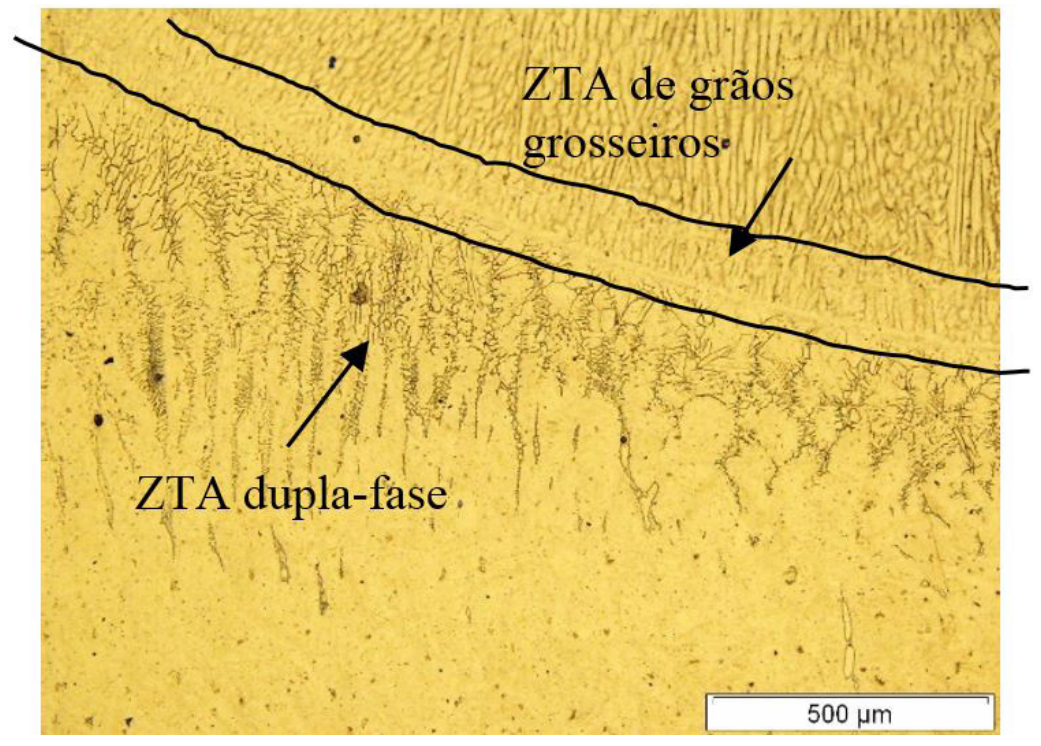

Figura 13. Regiões presentes na ZTA do CP1. As flechas apontam a região de grãos grosseiros e a região de dupla-fase. Ataque: sulfúrico.

Para demonstrar mais claramente que existe uma concentração de ferrita $\delta$ na ZTA-DF, foi feito também o ataque utilizando o reagente Stock. Esse ataque demonstra que a $\delta$ está presente entre os contornos de grãos.

A Figura 14 demonstra a presença então da ferrita $\delta$ nos contornos de grão do CP1 na região da ZTA-DF.

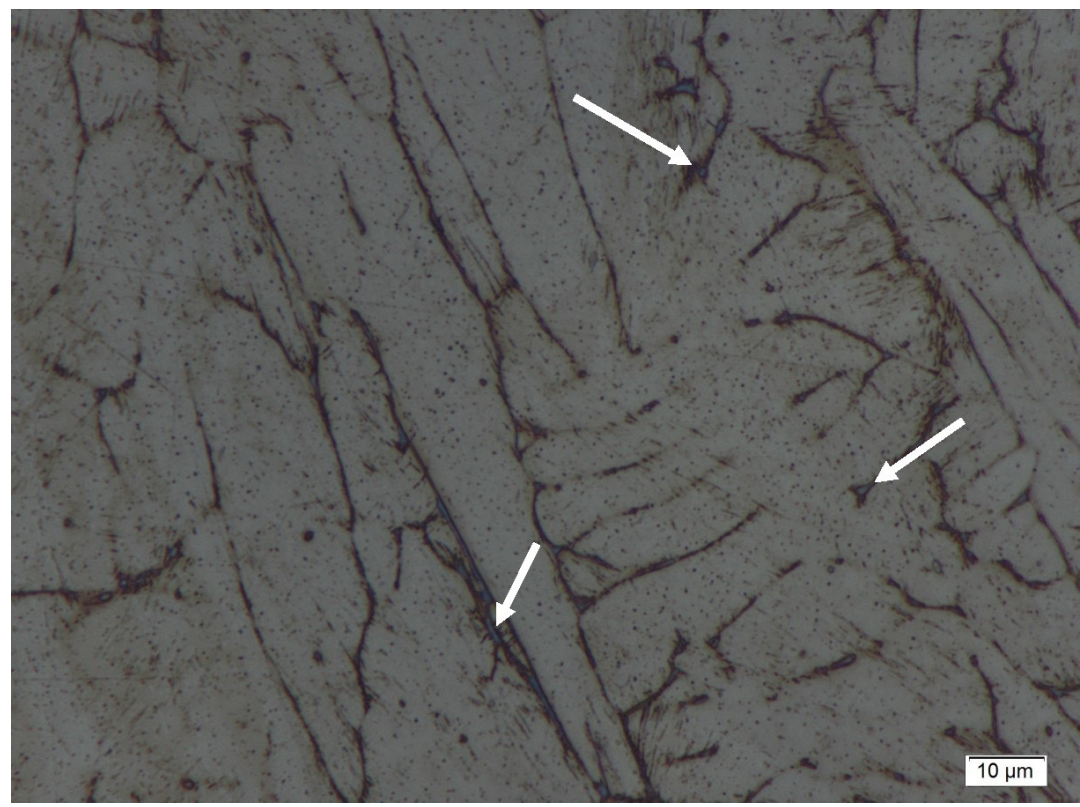

Figura 14. Ampliação de 50x da ZTA-DF do CP1. As flechas apontam a ferrita $\delta$ (em azul). Ataque: Stock. 
Logo abaixo da ZTA-DF, é possível observar a presença da ferrita $\delta$ como ilhas isoladas (Figura 15) e, como apontado também no trabalho de Ferreño et al. [8], existem algumas pequenas trincas que se propagam ao longo dos grãos da ferrita dispersos na matriz de martensita. Esse resultado também está de acordo com o trabalho de Wang et al. [6], onde o ensaio de Charpy provocou trincas nas regiões onde se localizavam ilhas de ferrita $\delta$.

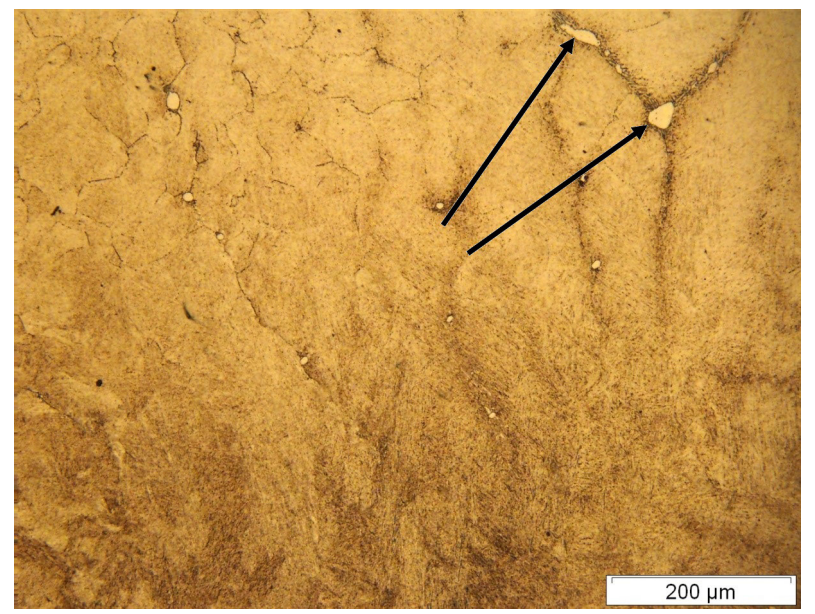

Figura 15. ZTA do CP5. É possível ver ilhas de ferrita $\delta$ apontadas nas flechas. Ataque: sulfúrico.

Foi observado que a quantidade de ferrita $\delta$ presente em cada cordão varia do passe superior para os inferiores. Foi possível identificar que existe uma maior quantidade de ferrita $\delta$ no cordão superior do que nos outros cordões. A Figura 16 demonstra também para o CP5 a diferença entre e cordão superior e o cordão logo abaixo com relação à presença dessa fase.

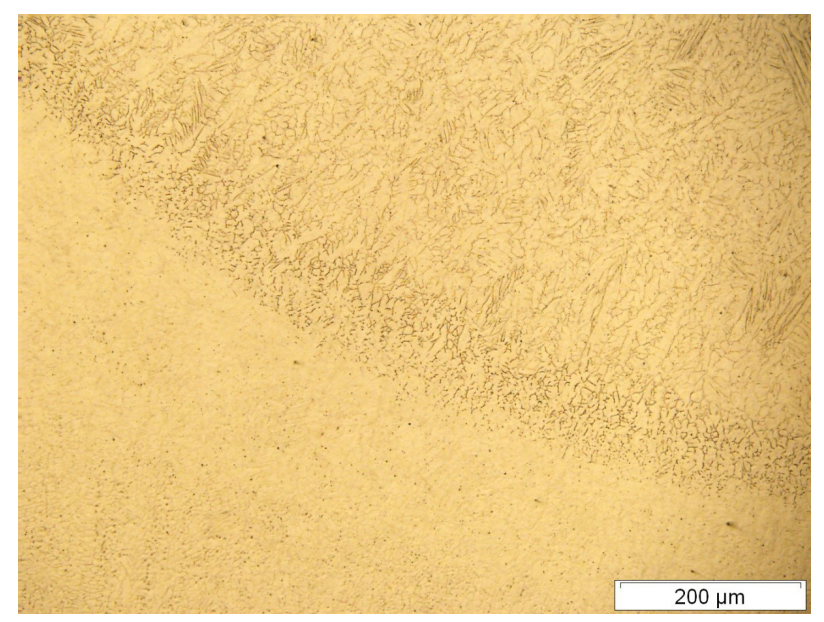

Figura 16. Região de interpasse entre o cordão superior e o cordão médio. Ataque: Sulfúrico.

Através então da binarização da imagem, foram levantadas as porcentagens de ferrita em cada passe, para verificar se todos os $\mathrm{CP}$ apresentavam um comportamento semelhante, ou seja, com o cordão superior retendo maior quantidade de ferrita que os inferiores. O resultado é mostrado na Figura 17.

Em todas as amostras, o cordão superior apresentou uma maior porcentagem de ferrita $\delta$, enquanto cordão do meio e o inferior apresentaram variações, mas na maioria das vezes, sendo o cordão inferior o que apresentou a menor quantidade dessa fase. Através da análise de Taguchi foi levantado o ranking de qual parâmetro influencia mais na retenção da ferrita. $O$ resultado é apresentado na Tabela 3. 
Formação de Ferrita Delta na Soldagem de Aço Inoxidável Super Martensítico tipo CA6NM pelo Processo Plasma PTA

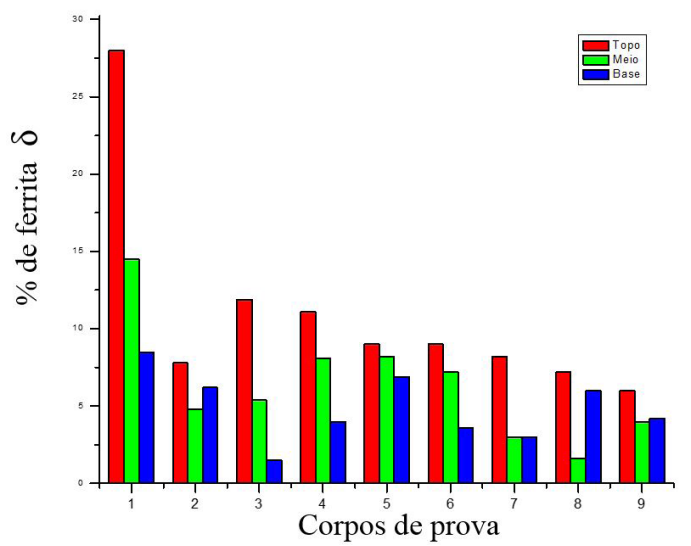

Figura 17. Quantidade de ferrita $\delta$ em porcentagem para os cordões de topo, do meio e da base de cada CP.

Como mostrado na Tabela 4, a corrente se mostrou o parâmetro mais significativo na retenção da ferrita $\delta$, sendo ranqueado em primeiro lugar, como já previsto através da análise da variância, indicando o motivo de, na Figura 17, termos menores \% de ferrita nos $C P 7,8$ e 9 se comparados com os $C P 1,2$ e 3, por exemplo. Na Figura 18, é mostrado o gráfico que demonstra a porcentagem de ferrita $\delta$ para cada fator em cada nível.

Tabela 4. Ranking de influência dos parâmetros para a \% de ferrita $\delta$.

\begin{tabular}{cccc}
\hline Nível & Recuo do eletrodo & Pós aquecimento & Corrente \\
1 & 9,822 & 10,144 & 9,844 \\
2 & 6,633 & 5,867 & 7,678 \\
3 & 5,867 & 6,311 & 4,800 \\
Delta & 3,956 & 4,278 & 5,044 \\
Ranking & $\mathbf{3}$ & $\mathbf{2}$ & $\mathbf{1}$ \\
\hline
\end{tabular}

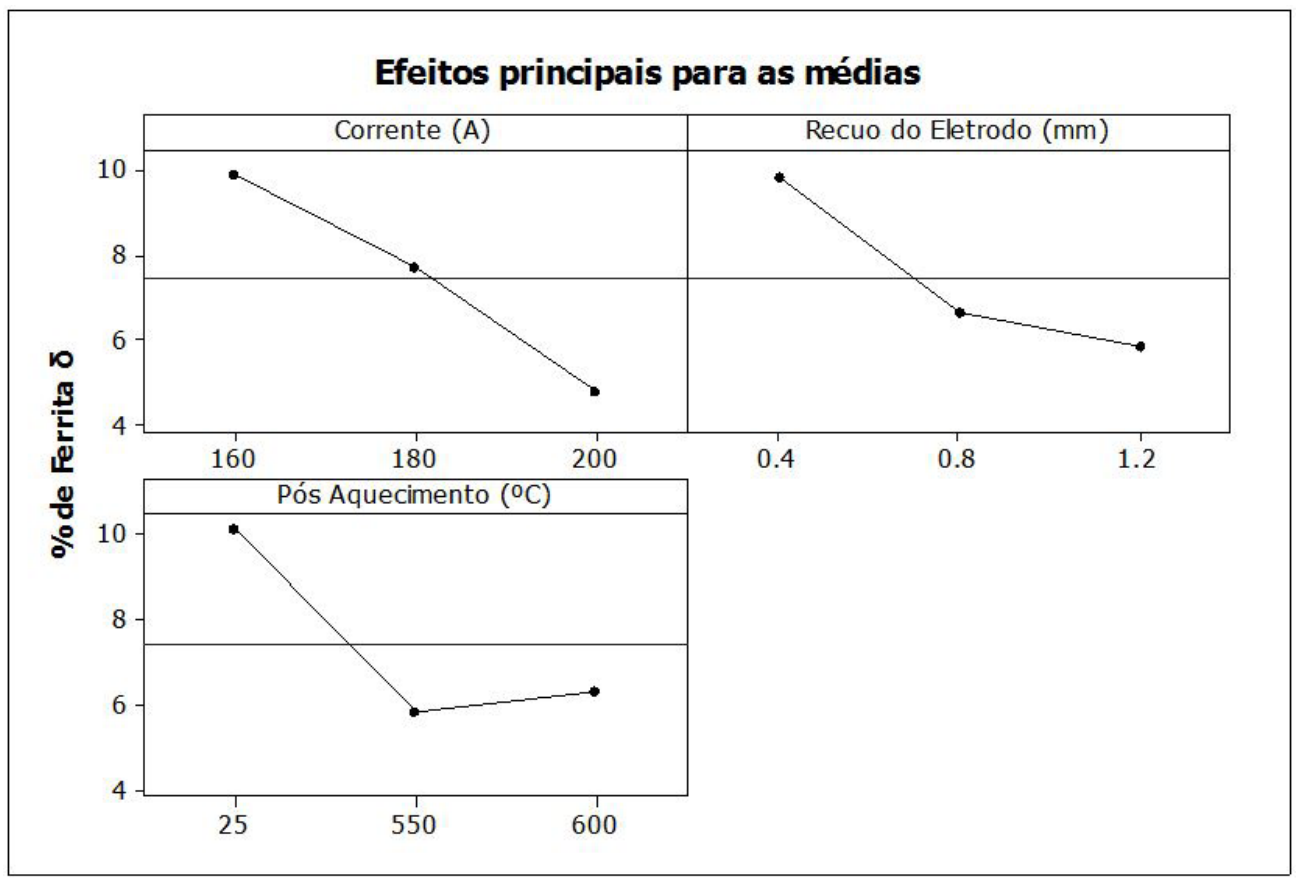

Figura 18. Efeitos principais dos parâmetros para a porcentagem média de ferrita $\delta$ retida. 
Através do gráfico, é percebido que a corrente de 200 A reteve menos quantidade de ferrita $\delta$. Uma explicação possível é que uma corrente mais alta provoca um maior aporte de calor na peça; esse calor faz com que a peça resfrie mais lentamente do que uma peça soldada com $160 \mathrm{~A}$, por exemplo. Esse tempo de resfriamento mais alto permite a transformação então da ferrita $\delta$ em austenita e, posteriormente, em martensita. Esse resultado entra em acordo com o trabalho de Carrouge [4] que afirma que uma maior taxa de resfriamento também implica em uma maior quantidade de ferrita $\delta$ retida na microestrutura. Com relação aos outros parâmetros (recuo do eletrodo e pós aquecimento), a variação foi mínima, sendo que esses parâmetros não se mostraram influentes no quesito retenção da ferrita $\delta$. $O$ pós aquecimento na faixa de 550 a $600{ }^{\circ} \mathrm{C}$ não provoca alterações metalúrgicas com relação à essa fase, pois só existe transformação da ferrita acima dos $1200^{\circ} \mathrm{C}$.

\section{Conclusões}

Foi evidenciada a presença da ferrita $\delta$ em todos os $\mathrm{CP}$, independente do conjunto de parâmetros utilizados.

$O$ cordão superior apresentou uma maior quantidade de ferrita $\delta$ e, sendo ela prejudicial para a tenacidade do material, recomenda-se então um passe subsequente para que haja uma dissolução dessa fase.

A morfologia intergranular observada por Gouveia [11] para uma temperatura de interpasse de $80^{\circ} \mathrm{C}$ não se repetiu nos resultados do presente trabalho provavelmente devido às correntes empregadas serem mais elevadas e a temperatura de pico atingir o campo monofásico da ferrita $\delta$, resultando assim na presença dessa fase entre as placas de austenita de Widmanstätten.

O valor de corrente de $200 \mathrm{~A}$ apresentou uma menor porcentagem de ferrita $\delta$ do que os valores de $160 \mathrm{~A} \mathrm{e} 180 \mathrm{~A}$, provavelmente devido ao resfriamento mais lento proporcionado pelo maior aporte térmico dos $\mathrm{CP}$ soldados com corrente mais elevada.

Os outros parâmetros (pós aquecimento e recuo do eletrodo) mostraram-se pouco influentes na retenção da ferrita $\delta$, não afetando significativamente os resultados.

\section{Agradecimentos}

Ao instituto LACTEC e à Companhia Paranaense de energia elétrica - COPEL, pelo suporte financeiro dado para aquisições dos materiais e execução dos ensaios.

\section{Referências}

[1] Agência Nacional de Energia Elétrica. Capacidade de geração do Brasil [on-line]. Brasília: ANEEL; 2014 [acesso em 10 abr. 2014]. Disponível em: http://www.aneel.gov.br/aplicacoes/ capacidadebrasil/capacidadebrasil.cfm

[2] Lippold JC, Kotecki DJ. Welding metallurgy and weldability of stainless steels. 1st ed. Hoboken: John Wiley \& Sons; 2005.

[3] Folkhard E. Welding metallurgy of stainless steels. New York: Springer-Verlag Wien; 1988.

[4] Carrouge D. Study off the microstructure developing in the HAZ of a range of supermartensitic stainless steel. Cambridge: University of Cambridge; 2002.

[5] Sánchez-Cabrera VM, Rubio-González C, Ruíz-Vela JI, RamírezBaltazar C. Effect of preheating temperature and filler metal type on the microstructure, fracture toughness and fatigue crack growth of stainless steel welded joints. Materials Science and Engineering A. 2007;452-453:235-243.

[6] Wang P, Lu SP, Xiao NM, Li DZ, Li YY. Effect of delta ferrite on impact properties of low carbon $13 \mathrm{Cr}$-4Ni martensitic stainless steel. Materials Science and Engineering A. 2010;527:3210-3216.

[7] Henke SL, Müller M, Takano EH, Paredes RSC. Microestrutura e resistência à fadiga de um aço inoxidável martensítico macio refundido por tocha plasma. Soldagem \& Inspeção. 2014;19(1):5157. http://dx.doi.org/10.1590/S0104-92242014000100007.
[8] Thibault D, Bocher P, Thomas M. Residual stress and microstructure in welds of $13 \% \mathrm{Cr}-4 \% \mathrm{Ni}$ martensitic stainless steel. Journal of Materials Processing Technology. 2009;209(4):2195-2202.

[9] Ferreño Blanco D, Álvarez JA, Ruiz Matínez E, Hernández D. Failure analysis of a Pelton turbine manufactured in soft martensitic stainless steel casting. Engineering Failure Analysis. 2011;18(1):256-270.

[10] Brezina P. Martensitische chorm-nickel-stahle mit tiefem kohlenstoffgehalt. Zurich: Escher Wyss; 1980. (Escher Wyss Mitteilungen, p. 218-236).

[11] Rubens de Gouveia R, Anderson GMP, Capra AR, Henke SL, Okimoto PC. Efeito da temperatura interpasse na microestrutura, tenacidade ao impacto e propagação de trinca por fadiga de uniões soldadas por GTAW do aço ASTM A743-CA6NM. Soldagem \& Inspeção. 2012;18(1):127-136. http://dx.doi.org/10.1590/ S0104-92242013000200006.

[12] Reis RO, Scotti A. Fundamentos e prática da soldagem a plasma. São Paulo: Artliber Editora; 2007.

[13] Henke SL. Efeito da soldagem plasma pulsada na microestrutura e resistência à fadiga de um aço inoxidável supermartensítico [tese de doutorado]. Curitiba: Universidade Federal do Paraná; 2010. 